\title{
High Molecular Weight Mixed-Linkage Glucan as a Mechanical and Hydration Modulator of Bacterial Cellulose: Characterization by Advanced NMR Spectroscopy
}

Juan C. Muñoz-García, ${ }^{\dagger}$ Kendall R. Corbin, ${ }^{\dagger, \perp}$ Haider Hussain, ${ }^{\dagger}$ Valeria Gabrielli, ${ }^{\dagger}$ Todor Koev, ${ }^{\dagger, \ddagger}$ Dinu Iuga, ${ }^{\S}$ Andrew N. Round, ${ }^{\dagger}$ Deirdre Mikkelsen, $"$ Patrick A. Gunning, ${ }^{\ddagger}$ Frederick J. Warren, ${ }^{*}, \$$ and Yaroslav Z. Khimyak*, ${ }^{*}+$ (1)

${ }^{\dagger}$ School of Pharmacy, University of East Anglia, Norwich NR4 7TJ, U.K.

${ }^{\ddagger}$ Food, Innovation and Health, Quadram Institute Bioscience, Norwich Research Park, Norwich NR4 7UQ U.K.

${ }^{\S}$ Department of Physics, University of Warwick, Coventry CV4 7AL, U.K.

"QAAFI Centre for Nutrition and Food Sciences, The University of Queensland, St. Lucia Campus, Brisbane, Queensland 4070, Australia

Supporting Information

ABSTRACT: Bacterial cellulose (BC) consists of a complex threedimensional organization of ultrafine fibers which provide unique material properties such as softness, biocompatibility, and water-retention ability, of key importance for biomedical applications. However, there is a poor understanding of the molecular features modulating the macroscopic properties of $\mathrm{BC}$ gels. We have examined chemically pure $\mathrm{BC}$ hydrogels and composites with arabinoxylan (BC-AX), xyloglucan $(B C-X G)$, and high molecular weight mixed-linkage glucan (BC-MLG). Atomic force microscopy showed that MLG greatly reduced the mechanical stiffness of BC gels, while XG and AX did not exert a significant effect. A combination of advanced solid-state NMR methods allowed us to characterize the structure of $\mathrm{BC}$ ribbons at ultra-high resolution and to monitor local mobility and water interactions. This has enabled us to unravel the effect of $A X, X G$, and

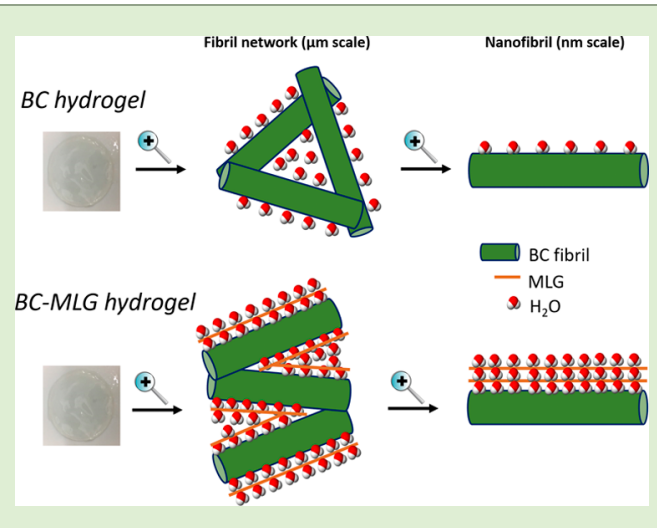
MLG on the short-range order, mobility, and hydration of BC fibers. Results show that $\mathrm{BC}-\mathrm{XG}$ hydrogels present $\mathrm{BC}$ fibrils of increased surface area, which allows $\mathrm{BC}-\mathrm{XG}$ gels to hold higher amounts of bound water. We report for the first time that the presence of high molecular weight MLG reduces the density of clusters of BC fibrils and dramatically increases water interactions with BC. Our data supports two key molecular features determining the reduced stiffness of BC-MLG hydrogels, that is, (i) the adsorption of MLG on the surface of BC fibrils precluding the formation of a dense network and (ii) the preorganization of bound water by MLG. Hence, we have produced and fully characterized BC-MLG hydrogels with novel properties which could be potentially employed as renewable materials for applications requiring high water retention capacity (e.g. personal hygiene products).

\section{INTRODUCTION}

Bacterial cellulose (BC) is produced by Gram-negative bacteria, such as Komagataeibacter xylinus (previously known as Acetobacter xylinum or Gluconacetobacter xylinum), and is chemically identical to plant cellulose $(\beta$-1,4-glucan) but has a different structural organization. Hence, unlike in plants, BC is secreted by bacteria as a pure polysaccharide into the surrounding environment and is hierarchically assembled into ribbons. While $\mathrm{BC}$ is synthesized in the absence of noncellulosic components and consists of microfibrils with crosssections of 4-8 nm, cellulose microfibrils of plant cell walls (PCWs) are synthesized embedded in a matrix of amorphous noncellulose polymers and present smaller cross-sections $(2-5$ $\mathrm{nm}){ }^{1}$
The production (yield and properties) of $\mathrm{BC}$ can be modified during biosynthesis by altering the culture conditions. BC can also be modified in situ by adding carbon nanotubes, ${ }^{2,3}$ lignosulfonate, ${ }^{4-6}$ polyaniline, ${ }^{7}$ and water soluble polysaccharides (e.g. hemicelluloses) $)^{1,8-10}$ to the growth media during biosynthesis. The added compounds become entrapped in the forming cellulose gel, modulating its macroscopic features such as morphology, crystalline index, water uptake capability, or electroconductivity. The ability to easily modify the gel properties of $\mathrm{BC}$ makes it an attractive biopolymer in the

Received: August 2, 2019

Revised: September 10, 2019

Published: September 13, 2019 
(a)

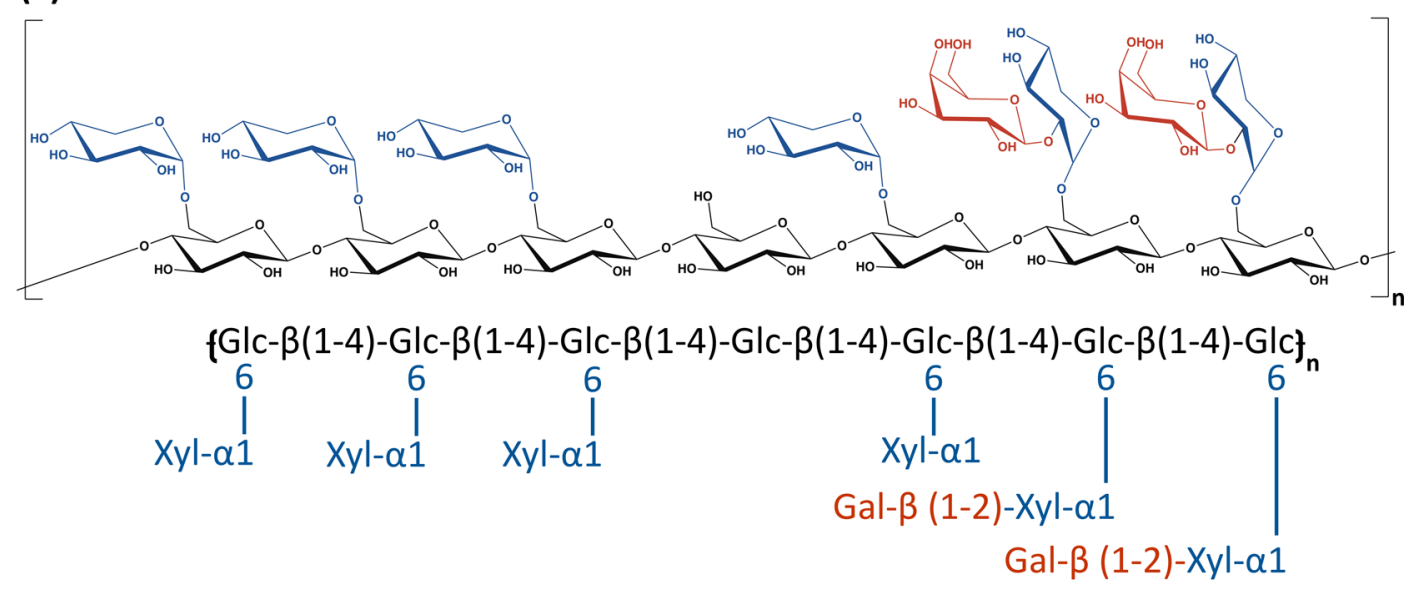

(b)

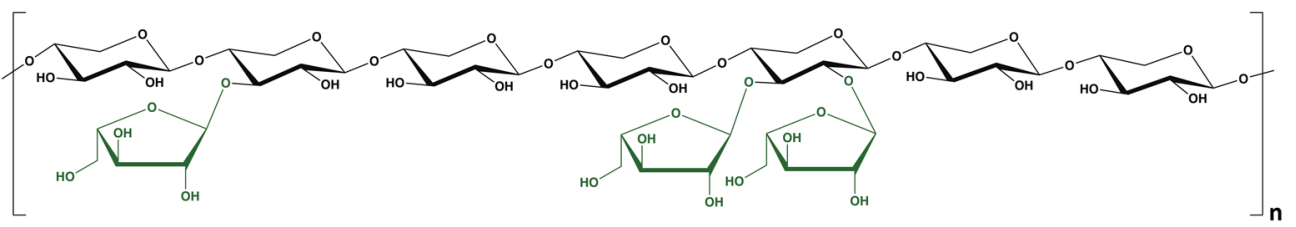

$-X y l-\beta(1-4)-X y l-\beta(1-4)-X y l-\beta(1-4)-X y l-\beta(1-4)-X y l-\beta(1-4)-X y l-\beta(1-4)-X y l-$

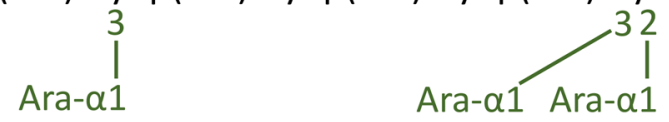

(c)

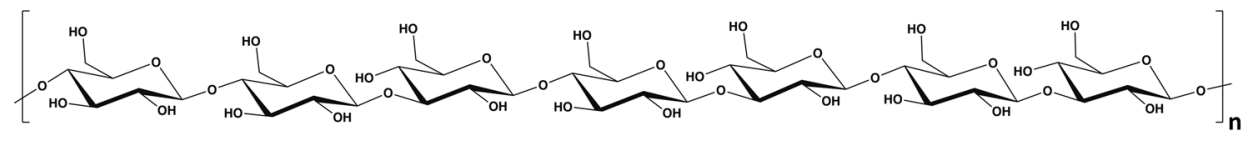

-Glc- $\beta(1-4)-G|c-\beta(1-3)-G| c-\beta(1-4)-G|c-\beta(1-3)-G| c-\beta(1-4)-G|c-\beta(1-3)-G| c-$

Figure 1. Representative repeating units of the chemical structure of (a) XG $\left(M_{\mathrm{w}}=1028 \mathrm{kDa}\right),{ }^{26}$ (b) AX $\left(M_{\mathrm{w}}=323 \mathrm{kDa}\right.$; Ref: Megazyme), and (c) $\operatorname{MLG}\left(M_{\mathrm{w}}=470 \mathrm{kDa}\right){ }^{27}$

pharmaceutical, food, and cosmetic industries and in biomedical applications such as drug delivery. ${ }^{11}$

BC has also been used as a scaffold to study polysaccharidepolysaccharide interactions and as a model system for PCWs. ${ }^{1,8,10,12-15}$ In particular, there are strong resemblances between hemicellulose-BC and hemicellulose-PCW interactions. ${ }^{14,16}$ For instance, it has been shown that hemicellulose interactions with $\mathrm{BC}$ can modulate the material properties of BC hydrogels. ${ }^{1,8,17,18}$ Attempts to better understand the effect of the incorporation of individual PCW polysaccharides such as mannan, ${ }^{19}$ arabinoxylan (AX) ${ }^{9}$ xyloglucan (XG), ${ }^{1}$ mixedlink glucan (MLG), ${ }^{9}$ and pectins ${ }^{16,20}$ have been reported. Some studies have suggested that only XG and mannans are able to interfere with the cellulose crystallization process by intercalating between cellulose chains, thus reducing the crystallinity index and promoting the formation of the cellulose $I_{\beta}$ allomorph and reducing significantly gel stiffness. ${ }^{8,17,19}$ In addition, a different population of $\mathrm{XG}$, which binds to the surface of cellulose ribbons, has been identified. This fraction is thought to correspond to the thin XG cross-bridges detected in the microscopy images from composite hydrogels. ${ }^{18}$ On the other hand, it has been reported that AX and MLG only affect the mechanical properties of $\mathrm{BC}$ composite hydrogels in a minor extent compared to XG and pectin. Based on these results, it was proposed that AX and MLG bind only to the surface of cellulose ribbons, following an entropically driven mechanism. ${ }^{1,8,9,15,21}$ However, none of the mentioned studies have investigated hydrogel network dynamics or water behavior in relation to the mechanical properties of $\mathrm{BC}$ hydrogels. These are important understudied characteristics of $\mathrm{BC}$ hydrogels due to their high water holding capacity (ca. 99 wt $\% \mathrm{H}_{2} \mathrm{O}$ ), which is a key aspect of many applications of $\mathrm{BC}$ hydrogels. ${ }^{1,22}$ For example, in commercial biomedical applications of $\mathrm{BC}$ hydrogels, the water holding and adsorptive capabilities of the materials are key to their applications as wound dressings, ${ }^{23,24}$ but the dynamics of water within BC hydrogels, and how to modify this behavior, have received little research interest.

Herein, by following a combined approach including advance solid-state NMR, X-ray diffraction (XRD), rheology, and microscopy, we have unraveled the molecular features responsible for the material properties of $\mathrm{BC}$ composites with the noncellulosic polysaccharides $\mathrm{AX}, \mathrm{XG}$, and high molecular weight MLG. To do so, we have studied hydrated ${ }^{13} \mathrm{C}$-labeled cellulose fibrils in the presence and absence of nonlabeled hemicelluloses and investigated water-polysaccharide interactions on the material properties of these hydrogels. In particular, we have characterized (i) the degree of short 
Table 1. Sugar Composition of AX, XG, and MLG, as Reported in the Literature and/or Provider

$\begin{array}{lcccc}\text { hydrogel } & \text { \% glucose } & \text { \% galactose } & \text { \% xylose } & \text { \% arabinose } \\ \mathrm{BC}^{-\mathrm{AX}^{a}} & 0 & 0 & 62 & 38 \\ \mathrm{BC}^{2} \mathrm{XG}^{26} & 45 & 17 & 34 & 2 \\ \mathrm{BC}-\mathrm{MLG}^{27} & 100 & 0 & 0 & 0\end{array}$

${ }^{a}$ Information obtained from Megazyme website (https://secure.megazyme.com/Arabinoxylan-Wheat-Flour-Medium-Viscosity).

(NMR) and long range [powder XRD (PXRD)] ordering, (ii) the crystalline allomorphism of $\mathrm{BC}$, (iii) the local dynamics of the interior and partially disordered surface domains of $\mathrm{BC}$ ribbons at different time scales, (iv) the mobility of $\mathrm{XG}$ and MLG within the gel, and (v) the interactions of water with the BC particle network at site-specific resolution. To the best of our knowledge, the findings herein characterize $\mathrm{BC}$ gels at the highest reported resolution, and for the first time, we demonstrate that high molecular weight MLG reduces the mechanical strength of $\mathrm{BC}$ hydrogels and acts as a waterstructuring coadjuvant for $\mathrm{BC}$. The proposed methodology assessing structure, dynamics, and properties of $\mathrm{BC}$ hydrogels at different lengths scales and focusing on the role of hydration in directing functional applications of carbohydrate-based hydrogels forms a tool-kit which should be valuable for understanding other classes of "soft" biomaterial systems.

\section{MATERIALS AND METHODS}

Production of BC Composite Hydrogels. K. xylinus (formerly Gluconacetobacter xylinus, strain ATCC 53524) was cultivated in Hestrin and Schramm medium ( $\mathrm{pH} 5.0)$ containing 2\% (w/v) glucose (Merck, UK) or $2 \%(\mathrm{w} / \mathrm{v}){ }^{13} \mathrm{C}$-labeled glucose (Cambridge Isotope Laboratories Inc., USA). ${ }^{9} \mathrm{BC}$-hemicellulose composites were produced by adding medium viscosity $(31 \mathrm{cSt}$ ) wheat $\mathrm{AX}$ (Megazyme International Ireland), tamarind seed XG (Megazyme International Ireland), or high-molecular weight (650000 Da) MLG (Nofima, Tromsø, Norway) (Figure 1, Table 1) to the medium at a concentration of $0.5 \%(\mathrm{w} / \mathrm{v}) .^{25}$ Incubations were performed under static conditions at $30{ }^{\circ} \mathrm{C}$ for $72 \mathrm{~h}$ and thereafter washed with $0.02 \%$ $(\mathrm{w} / \mathrm{v})$ sodium azide in $0.1 \mathrm{M} \mathrm{NaOH}(24 \mathrm{~h})$, followed by two washes $(24 \mathrm{~h})$ with $0.02 \%(\mathrm{w} / \mathrm{v})$ sodium azide. The washing steps were done at $30^{\circ} \mathrm{C}$ by gentle agitation $(50 \mathrm{rpm})$.

Compositional Analysis. Hemicellulose incorporation into the various $\mathrm{BC}$ composites was determined as previously described by Pettolino et al. $(2012)^{28}$ with the following modifications. Briefly, for each composite material in duplicate, the freeze-dried sample $(5 \mathrm{mg})$ was hydrolyzed at room temperature for $1 \mathrm{~h}$ in $12 \mathrm{M} \mathrm{H}_{2} \mathrm{SO}_{4}(200$ $\mu \mathrm{L})$, then diluted with Milli-Q water $(2.75 \mathrm{~mL})$, and incubated at 100 ${ }^{\circ} \mathrm{C}$ for $3 \mathrm{~h}$. Thereafter, samples were cooled and neutralized with $\mathrm{NH}_{4} \mathrm{OH}(500 \mu \mathrm{L})$; the internal standard (5 mg of myo-inositol) was added to each sample and then dried under a stream of nitrogen. Hydrolyzed samples were reduced with $200 \mu \mathrm{L} \mathrm{NaBD}_{4}$ in dimethyl sulfoxide $\left(20 \mathrm{mg} \mathrm{mL}^{-1}\right)$ at $40{ }^{\circ} \mathrm{C}$ for $1.5 \mathrm{~h}$. Acetic acid $(20 \mu \mathrm{L})$ was added to destroy the reductant and then acetylated with 1methylimidazol $(25 \mu \mathrm{L})$ and acetic anhydride $(250 \mu \mathrm{L})$. After 10 min, Milli- $\mathrm{Q}$ water $(2 \mathrm{~mL})$ was added, followed by dichloromethane $(\mathrm{DCM}-1 \mathrm{~mL})$ to extract the alditol acetates. After mixing, samples were centrifuged to aid phase separation and the DCM phase was washed twice with Milli- $\mathrm{Q}$ water $(2 \mathrm{~mL})$, after which it was dried under a stream of nitrogen, reconstituted to $500 \mu \mathrm{L}$ of DCM and analyzed by gas chromatography attached to a mass spectrophotometer on a high polarity BPX70 column.

Total Moisture Content Analysis. Moisture content of all BC hydrogel samples was measured using a TA Instruments (TA Instruments Ltd., New Castle, USA) thermogravimetric analyzer (TGA) Discovery series TGA5500, using TA Instruments standard open aluminium pans (reference number 900786.901), where 3-5 mg samples were excised with minimal deformation using a surgical blade and loaded onto pretared pans. No initial weight equilibration step was used, in order to minimize the water evaporation from BC hydrogels prior to the experimental procedure. The change in sample weight was recorded at increments of $0.05 \mathrm{~s}$ in the temperature range of $25-200{ }^{\circ} \mathrm{C}$, at a heating rate of $5{ }^{\circ} \mathrm{C} / \mathrm{min}$. The point of complete moisture loss was determined as the lowest temperature at which no further significant mass loss was observed, which for all samples was in the range of $90-150{ }^{\circ} \mathrm{C}$. The total moisture content was determined as the mass difference $(\% \mathrm{w} / \mathrm{w})$ from the start of the experiments to the point of complete moisture loss for each sample. Data presented is the average of a minimum of three replicates.

Dynamic Oscillatory Rheology. Dynamic rheology was performed on a TA Instruments (TA Instruments Ltd., New Castle, USA) Rheometer AR2000, with $13 \mathrm{~mm}$ parallel plate geometry, equipped with a Peltier device for temperature control, where hydrogel samples were excised using a $13 \mathrm{~mm}$ cork borer (Breckland Scientific Supplies Ltd., Stafford, UK) with minimal manipulation and excess sodium azide $(0.02 \% \mathrm{w} / \mathrm{v})$ solution was blotted using Kimtech precision wipes (Kimberly-Clark Professional). BC gels were loaded onto the sensor plate and left for 2 min to allow the temperature to equilibrate, minimizing the impact of loading effects. Samples were analyzed at a constant temperature of $5{ }^{\circ} \mathrm{C}$ and the interplate gap was set to $2.0 \mathrm{~mm}$. All rheological data were analyzed using TA Data Analysis software package, establishing the linear viscoelastic (LVE) region, the storage and loss moduli ( $G^{\prime}$ and $G^{\prime \prime}$, respectively) and phase angle tangent $(\tan \delta)$ of all hydrogel samples.

Strain sweeps were performed in the range of $0.01-100 \%$ at a constant frequency of $0.1 \mathrm{~Hz}$ to ascertain the materials' LVE range. This was followed by frequency sweep analyses in the range of $0.01-$ $10.0 \mathrm{~Hz}$ at a constant strain of $0.025 \%$ to determine the behavior of each sample's individual storage modulus $\left(G^{\prime}\right)$, loss modulus $\left(G^{\prime \prime}\right)$, and phase angle tangent $(\tan \delta)$ as a function of angular oscillatory frequency. All measurements were taken at regular time intervals, and the data presented are averages of a minimum of three runs.

BC Gel Thickness. BC hydrogel thickness was measured using a TA Instruments (TA Instruments Ltd., New Castle, USA) Rheometer AR2000, equipped with $13 \mathrm{~mm}$ parallel plate geometry, where excised samples were loaded onto the Peltier device, followed by the lowering of the upper parallel plate until contact was established across the entirety of the upper plate, as detected by the rheometer. Sample thickness was determined as the gap distance between the upper plate and the Peltier device at the point of upper plate contact with the sample. Data presented is the average of a minimum of three measurements on the same gel.

X-ray Diffraction. XRD (Thermo ARL, Xtra fitted with $\mathrm{Cu}$ X-ray tube, $45 \mathrm{kV}, 40 \mathrm{~mA})$ with $\mathrm{Cu} \mathrm{K} \alpha$ radiation $(\lambda=0.154 \mathrm{~nm})$ was used to examine the crystal structure of the BC, XG, AX, MLG alone, and their blend. Diffraction angles $(2 \Theta)$ ranging from 5 to $55^{\circ}$ were employed. All the hydrogels were analyzed in the freeze-dried form and cut into small pieces. $\mathrm{XG}, \mathrm{AX}$, and MLG were analyzed in the powder form.

Scanning Electron Microscopy. Hydrogels were placed into a solution of $2.5 \%$ glutaraldehyde in $0.1 \mathrm{M}$ PIPES buffer ( $\mathrm{pH} 7.4)$ and fixed overnight. After washing with 0.1 M PIPES buffer, the gel was cut into approximately $5 \mathrm{~mm}^{3}$ pieces, inserted into a critical point drying capsule, and dehydrated in a series of ethanol solutions $(30,50$, $70,80,90,3 \times 100 \%)$. The gels were then dried in a Leica EM CPD300 Critical Point Dryer using liquid carbon dioxide as the transition fluid. The dry gel material was carefully torn across using a razor blade and tweezers and was mounted with the freshly torn surface facing upward onto scanning electron microscopy (SEM) stubs using conductive silver paint. The samples were coated with 
gold in an Agar high resolution sputter-coater apparatus. SEM was carried out using a Zeiss Supra 55 VP FEG SEM, operating at $3 \mathrm{kV}$.

Atomic Force Microscopy. The atomic force microscope used in this study was an MFP-3D BIO (Asylum Research, Goleta, CA, USA). The experimental data were captured in a so-called force-volume mode using a colloidal CP-PNP-SiO probe with a $2 \mu \mathrm{m}$ sphere in PBS (at a rate of $2 \mu \mathrm{m} / \mathrm{s}$ in the $Z$ direction and at a scan rate of $1 \mathrm{~Hz}$ and a pixel density of $32 \times 32$ ). In this mode, the instrument ramps the $Z$ piezo element of the scanner by a predetermined amount at each sample point over a selected scan area $(3 \mu \mathrm{m})$ and records the subsequent deflection of the cantilever as it is pushed into (maximum load forces of 10,20 or $40 \mathrm{nN}$ ) and then retracted away from the sample surface. This produces a matrix of 1024 force versus distance curves for each tip-sample combination. The spring constant, $k$, of the cantilevers was determined by fitting the thermal noise spectra, ${ }^{29}$ yielding typical values in the range $0.01-0.04 \mathrm{~N} / \mathrm{m}$. Young's moduli for the gels were determined by fitting the Hertz model of contact mechanics. ${ }^{30}$ The Hertz model has proven sufficient for modeling of atomic force microscopy (AFM) data on soft biological samples. ${ }^{31}$ Its use is favored here by the fact that it does not require prior knowledge of parameters like surface energy, which are difficult to measure accurately for the kinds of surfaces (often microheterogeneous) common in biological systems. In the current application, the forcedistance plots extracted from force-volume datasets of the $\mathrm{BC}$ and $\mathrm{BC}$-hemicellulose gels and glass, an ideally hard reference, are compared in order to determine the indentation, $\delta$, of the tip into the gels at a given force. The indentation at a given force is defined as the depth of penetration of the tip into the sample surface. It is calculated with reference to an ideally hard surface, in this case glass, where the indentation is set at 0 . The relationship between loading force $F$ and indentation $\delta$ is then given by eq 1

$$
F=\frac{4 E \sqrt{R}}{3\left(1-\mu^{2}\right)} \delta^{3 / 2}
$$

where $E$ is Young's modulus, determined as a fitting parameter, $R$ is the AFM tip radius (given above as $2 \mu \mathrm{m}$ ), and $\mu$ is the Poisson ratio for the deformable gel, here taken to be 0.5 .

Solid-State NMR. Solid-state NMR experiments were carried out using either a Bruker AVANCE III $400 \mathrm{MHz}$ spectrometer equipped with a HXY $4 \mathrm{~mm}$ probe or a Bruker AVANCE III $850 \mathrm{MHz}$ solidstate NMR spectrometer (UK National 850 Solid-State NMR facility at Warwick) equipped with a $3.2 \mathrm{~mm}$ HXY low E field H13900 probe. Experiments were acquired at MAS spinning rates of 6 and $12 \mathrm{kHz}$ when using the 4 and $3.2 \mathrm{~mm}$ probes, respectively. Tetramethylsilane was used as an external chemical shift reference for ${ }^{1} \mathrm{H}$ and ${ }^{13} \mathrm{C} . \pi / 2$ pulses of 3.5 and $4.5 \mu$ s were used for ${ }^{1} \mathrm{H}$ and ${ }^{13} \mathrm{C}$, respectively. A relaxation delay of 1 and $100 \mathrm{~s}$ were used for mobility-enhanced and quantitative ${ }^{13} \mathrm{C}$ DP experiments, respectively, and $10 \mathrm{~s}$ for ${ }^{1} \mathrm{H}-{ }^{13} \mathrm{C}$ cross polarization $(\mathrm{CP})$ experiments.

${ }^{13} \mathrm{C}-{ }^{13} \mathrm{C}$ refocused CP-INADEQUATE experiments on ${ }^{13} \mathrm{C}$ labeled gels were carried out on the $850 \mathrm{MHz}$ spectrometer at Warwick, at $12 \mathrm{kHz}$ magic angle spinning. A relaxation delay of $2 \mathrm{~s}$ and a $2 \tau$ spin-echo evolution time for a $(\tau-\pi-\tau)$ spin-echo of $5 \mathrm{~ms}$ were employed. All the experiments were carried out at $25^{\circ} \mathrm{C}$ and/or $5{ }^{\circ} \mathrm{C}$.

Determination of the surface-to-interior $(\mathrm{s} / \mathrm{i})$ ratio and percentage of $I_{\alpha}$ allomorph $\left(\% I_{\alpha}\right)$ of $\mathrm{BC}$ hydrogels by ${ }^{13} \mathrm{C}$ quantitative direct polarization (DP) and ${ }^{1} \mathrm{H}-{ }^{13} \mathrm{C} \mathrm{CP}$ NMR experiments.

DP experiments using high power ${ }^{1} \mathrm{H}$ decoupling were carried out using a $100 \mathrm{~s}$ relaxation delay to obtain quantitative ${ }^{13} \mathrm{C}$ spectra, taking into account that the maximum ${ }^{13} \mathrm{C} T_{1}$ times measured were 12 $\mathrm{s}$ (Table S7). The surface-to-interior $(\mathrm{s} / \mathrm{i})$ ratio of $\mathrm{BC}$ was derived by spectral deconvolution of the $\mathrm{C} 4$ peaks corresponding to the crystalline interior $\left(A_{\mathrm{iC} 4}\right)$ and partially disordered surface $\left(A_{\mathrm{sC} 4}\right)$ domains of cellulose (Figure 3 ) and using the following equation

$$
\mathrm{s} / \mathrm{i}=\frac{A_{\mathrm{sC} 4}}{A_{\mathrm{iC} 4}}
$$

For the quantification of $\mathrm{BC}$ allomorphs among different hydrogels, the percentage of $I_{\alpha}$ allomorph ( $\left.\% I_{\alpha}\right)$ was obtained by deconvolution of the iC4 peak on ${ }^{1} \mathrm{H}-{ }^{13} \mathrm{C} \mathrm{CP}$ NMR spectra acquired at $20 \mathrm{~T}$, using the following equation ${ }^{32}$

$$
\% I_{\alpha}=\frac{A_{\mathrm{iC} 4, I_{\alpha}}+\frac{1}{2} A_{\mathrm{iC} 4, I_{\alpha}+I_{\beta}}}{A_{\mathrm{iC} 4, \text { total }}}=\frac{A_{\mathrm{iC} 4, I_{\alpha}}+\frac{1}{2} A_{\mathrm{iC} 4, I_{\alpha}+I_{\beta}}}{A_{\mathrm{iC} 4, I_{\alpha}}+A_{\mathrm{iC} 4, I_{\alpha}+I_{\beta}}+A_{\mathrm{iC} 4, I_{\beta}}}
$$

The experiments were run on ${ }^{13} \mathrm{C}$-labeled $\mathrm{BC}, \mathrm{BC}-\mathrm{AX}$, and $\mathrm{BC}-$ ML gels and unlabeled $\mathrm{BC}-\mathrm{XG}$ gel, the latter due to large broadening (strong ${ }^{13} \mathrm{C}$ homonuclear dipolar coupling) of the labeled gel precluding differentiation of $I_{\alpha}$ and $I_{\beta}$.

Data Analysis of CP Kinetics Curves. Different models for the analysis of $\mathrm{CP}$ growth over contact time, also called CP kinetics, have been developed. The simplest model of CP kinetics (I-S) was derived for homogeneous solids where the I-S heteronuclear interactions are relatively weak and the I-I homonuclear dipolar interactions are strong to provide efficient spin diffusion. For a system of abundant (I) and diluted (S) 1/2 spin nuclei, provided that the rate of I-S transfer of magnetization $\left(T_{\mathrm{IS}}{ }^{-1}\right)$ is faster than the relaxation rate in the rotating frame of the I spins $\left(T_{i \rho}^{\mathrm{I}}{ }^{-1}\right)$, that is, $T_{\mathrm{IS}} / T_{1 \rho}^{\mathrm{I}} \rightarrow 0$, the $\mathrm{I}-\mathrm{S}$ model leads to the kinetic equation

$$
I(t)=I_{0}\left(1-\frac{T_{\mathrm{IS}}}{T_{1 \rho}^{\mathrm{I}}}\right)^{-1}\left[\exp \left(-\frac{t}{T_{1 \rho}^{\mathrm{I}}}\right)-\exp \left(-\frac{t}{T_{\mathrm{IS}}}\right)\right]
$$

where $I(t)$ is the normalized peak intensity, $I_{0}$ is the absolute amplitude, $T_{1 \rho}^{\mathrm{I}}$ is the relaxation time of the abundant spin in the rotating frame, and $T_{\mathrm{IS}}$ is the $\mathrm{CP}$ time constant.

The fit of CP kinetics data to eq 4 allowed us to obtain $T_{1 \rho}^{1 \mathrm{H}}$ and $T_{\mathrm{CH}}$ values for $\mathrm{BC}$ rigid domains in the absence and presence of $\mathrm{AX}$, $\mathrm{XG}$, and MLG. $T_{\mathrm{CH}}$ reports on the efficiency of ${ }^{1} \mathrm{H}-{ }^{13} \mathrm{C}$ magnetization transfer and, therefore, on the rigidity of the individual $\mathrm{C}-\mathrm{H}$ vectors (the lower the $T_{\mathrm{CH}}$ parameter, the higher the rigidity). The fit of the experimental data was carried out with QtiPlot.

Mobility-Enhanced ${ }^{13} \mathrm{C}$ DP Experiments for the Determination of BC-Disordered Domains. An interesting application of ${ }^{13} \mathrm{C}$ DP experiments is to enhance the presence of mobile over rigid components in the spectra. ${ }^{33}$ This is achieved by employing a very short relaxation delay (1-2s). To obtain a rough estimation of the mobility of the surface (s) relative to the interior domains (i) of BC in the different hydrogels, we have defined a mobility index (MI) alike the $\mathrm{s} / \mathrm{i}$ ratio shown in eq 2 but using ${ }^{13} \mathrm{C}$ direct polarization experiments carried out using a very short relaxation delay

$$
\mathrm{MI}=\frac{A_{\mathrm{sC} 4}}{A_{\mathrm{iC} 4}} \cdot 100
$$

where $s A_{C 4}$ and $i A_{C 4}$ are the areas of the $\mathrm{C} 4$ peaks corresponding to surface and interior $\mathrm{BC}$ domains, respectively, from ${ }^{13} \mathrm{C}$ DP spectra recorded using $1 \mathrm{~s}$ relaxation delay. These experiments were acquired using a $20 \mathrm{~T}$ spectrometer operating at $12 \mathrm{kHz}$ MAS rate.

Water Polarization Transfer CP. The water polarization transfer $\mathrm{CP}$ experiment (WPT-CP) is a very powerful NMR technique to gain insights on the hydration profile of solid particles at the atomistic level. ${ }^{34}$ It starts with a ${ }^{1} \mathrm{H} \mathrm{T}_{2}$ filter that is optimized to remove the transverse magnetization of the immobile components of the system (e.g. BC fibrils), while keeping most of the ${ }^{1} \mathrm{H}$ magnetization of the mobile constituents (e.g. water). This ${ }^{1} \mathrm{H}$ magnetization is then transferred to the immobile components by spin diffusion and chemical exchange during the mixing time period. Finally, a $\mathrm{CP}$ building block transfer ${ }^{1} \mathrm{H}$ magnetization to ${ }^{13} \mathrm{C}$ for detection.

A short contact time $(500 \mu \mathrm{s})$ was used to reduce the contribution of spin diffusion during $\mathrm{CP}$, so that the acquired signal is mostly affected by water proximity and mobility. ${ }^{34}$ It should be noted that the $T_{2}$ filter must be first optimized to reduce the less mobile peaks below $5 \%$ of their initial intensity. A $T_{2}$ filter of $2 \mathrm{~ms}$ was sufficient for our gels. Mixing times ranging from 1 to $324 \mathrm{~ms}$ was employed. The peak 
intensities at each mixing time were normalized against the spectrum giving the highest intensity peaks, that is, acquired with the longest mixing time (324 ms). By representing the normalized growth of peak area against the square root of mixing time, the spin diffusion profile of hydration at each ${ }^{1} \mathrm{H}-{ }^{13} \mathrm{C}$ site is obtained. All WPT-CP experiments were acquired at $293 \mathrm{~K}$.

\section{RESULTS AND DISCUSSION}

Production and Molecular Analysis of BC Composites in the Presence of $A X, X G$, and MLG. Pure $B C$, as well as composite gels containing $\mathrm{AX}, \mathrm{XG}$, and MLG were successfully produced using aerobic cultures of $K$. xylinus. The thickness of the gels produced was variable (Table S1); however, the water content was similar for all gels $(98-99 \% \mathrm{w} / \mathrm{w})$ (Tables 2 and

Table 2. Composition and Thicknesses for the BC Gel and BC Composite Gels ${ }^{a}$

\begin{tabular}{lccc} 
& $\begin{array}{c}\text { hemicellulose } \\
\text { incorporation } \\
(\% \text { w/w })\end{array}$ & $\begin{array}{c}\text { moisture content } \\
(\% \text { w } / w) \pm \text { S.D. }\end{array}$ & $\begin{array}{c}\text { temperature at point of } \\
\text { complete water loss } \\
\left({ }^{\circ} \mathrm{C}\right) \pm \text { S.D. }\end{array}$ \\
\hline BC & n.a. & $98.4 \pm 0.4$ & $117.0 \pm 9.9$ \\
BC-AX & 10.2 & $98.4 \pm 0.8$ & $109.0 \pm 15.5$ \\
BC-XG & 14.0 & $98.7 \pm 0.5$ & $141.7 \pm 5.8$ \\
BC-MLG & n.a.* & $98.7 \pm 0.3$ & $135.7 \pm 6.0$
\end{tabular}

${ }^{a}$ Standard deviations are from triplicate measurements. Not applicable (n.a.). *Incorporation data could not be determined as the BC-MLG gels only contain glucose.

S2). In particular, the incorporation of XG and MLG reduced gel thickness 2- to 3-fold (Table S1), which is in agreement with other studies. ${ }^{8}$ Monosaccharide analysis revealed that there was a higher level of incorporation of XG into the $\mathrm{BC}$ gels than AX (Tables 2 and S3), in line with previous work. ${ }^{35}$ In this study, MLG was not quantified as the monosaccharide analysis used cannot differentiate glucose from MLG and BC. However, CPSP NMR experiments provided clear evidence of MLG incorporation into the gel composite (Figure 5b).

Microstructure and Mechanical Properties of $B C$ Composites with $\mathrm{AX}, \mathrm{XG}$, and MLG. XRD and SEM. PXRD analysis was used to investigate the effect of additive polysaccharides ( $\mathrm{AX}, \mathrm{XG}$, and $\mathrm{MLG}$ ) on $\mathrm{BC}$ crystallinity and structure at the long-range length scale. $\mathrm{BC}$ and $\mathrm{BC}-\mathrm{AX}$ gels yielded well-defined diffraction peaks (Figure S2), indicating that ordered BC fibrils were formed. On the other hand, XG gave rise to the formation of the most disordered $\mathrm{BC}$ fibrils, followed by BC-MLG gels (increased peak broadening in the PXRD profile, Figure S2). No diffraction patterns were observed for the hemicellulose components, indicating they are disordered polymers (Figure S2).

SEM images of pure BC gels exhibited the mesh-like network structure of cellulose microfibrils typical of $\mathrm{BC}$ (Figure S3). A similar mesh-like structure can be seen for each of the composite hydrogels. There were no obvious differences observed between the composites and the pure BC. Previous authors have shown evidence of filamentous crosslinks between cellulose microfibrils in composite gels produced with XG. ${ }^{8}$ These could not be clearly seen in the present study. $\mathrm{AX}$ aggregates were not observed for the BC AX gels. The ca. 2 $\mu \mathrm{m}$ oval structures observed in some images are residual bacterial cells.

Rheological and AFM Assessment of Gel Rigidity. The micromechanics of the individual cellulose fibers and interactions with hemicelluloses affect the rheology of the bulk gel. ${ }^{8}$ The visual counting of 2D AFM maps (Figures S4S7) was carried out for three different probe forces applied $(10,20$ and $40 \mathrm{nN})$. The results (Figure 2) show a very similar

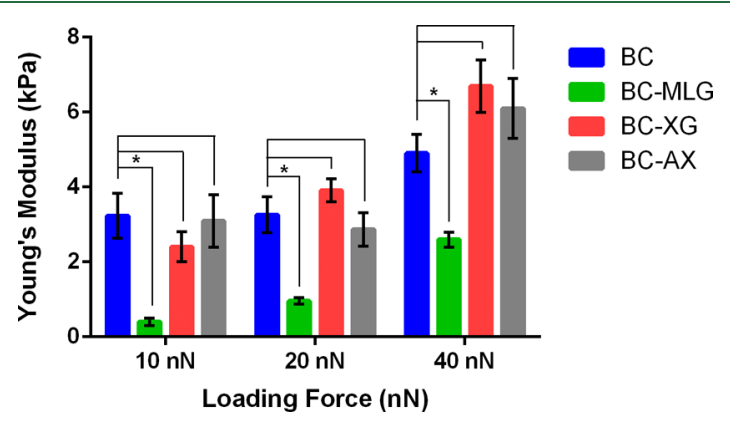

Figure 2. Plot of the average Young's modulus response of BC (blue), $\mathrm{BC}-\mathrm{AX}$ (grey), BC-XG (red), and BC-MLG (green) hydrogels for three different AFM probe forces applied (10, 20 and $40 \mathrm{nN}$ ). The Young's modulus values were obtained from visual analysis of AFM 2D maps. The error bars represent the standard deviation of the average values of a minimum of 144 measurements, calculated from the AFM 2D maps. ${ }^{*} p<0.05$ (unpaired two-tailed $t$-test).

strength for $\mathrm{BC}, \mathrm{BC}-\mathrm{AX}$, and $\mathrm{BC}-\mathrm{XG}$ (within the standard deviation), but a significantly $(p<0.05)$ lower stiffness for BC-MLG. This is in contrast with the oscillatory shear rheological data, which shows that the $G^{\prime}$ values for the gels decrease in the order $\mathrm{BC}>\mathrm{BC}-\mathrm{AX}>\mathrm{BC}-\mathrm{MLG}>\mathrm{BC}-\mathrm{XG}$ (Figure S8). However, the rheological behavior of cellulose hydrogels is known to be highly dependent on the gel thickness, and the $G^{\prime}$ values measured in this study correlate closely to gel thickness (Table S1). The micromechanics of the gel fibers measured by AFM (Figure 2) shows that for individual fibers or bundles of fibers, there is no significant difference in the mechanical properties of the $\mathrm{BC}, \mathrm{BC}-\mathrm{AX}$, and $\mathrm{BC}-\mathrm{XG}$ gels $(p>0.05)$. This finding is in agreement with recent AFM studies using "drag-and-dip" lateral force AFM experiments to probe adhesive forces and micromechanics of $\mathrm{BC}$ composites, which produced results suggesting that $\mathrm{BC}$, $\mathrm{BC}-\mathrm{AX}$, and $\mathrm{BC}-\mathrm{XG}$ have very similar micromechanical properties. ${ }^{36}$ Our observation that MLG significantly reduces the stiffness of cellulose fibers has, to the best of the authors' knowledge, not been previously reported. ${ }^{9}$ More generally, the discrepancy between AFM-based and rheological data on the BC-MLG gels may simply reflect the fact that the AFM indentation experiments probe only the region at and immediately beneath the gel surface, whereas the rheological experiments reflect the behavior of a much deeper section (as shown by their dependence on the gel thickness).

Local Structure and Dynamics of BC Composites with AX, XG, and MLG: Solid-State NMR Characterization. Ordered and Disordered Domains in BC Hydrogels. Among the accumulated literature on the structural characterization of cellulose-based materials, different models to describe a cellulose fibril have been proposed, and different names are used to refer to their ordered and disordered regions. ${ }^{37}$ For BC and PCWs, it is common to describe their fibrils as particles containing amorphous (or partially disordered) surface domains and crystalline (or ordered) core or interior domains. $^{34,38,39}$ Further, Wang and Hong proposed a more detailed model for PCW fibrils, ${ }^{38}$ which considers three regions in a $\mathrm{BC}$ microfibril, that is, the partially disordered surface (s), a surface-bound para-crystalline domain (b), and 
the crystalline core (c), where $b$ and $c$ form together the interior region (i). Thus, $s$ and $i$ represent the partially disordered and ordered domains, respectively. Herein, we have used this model for our NMR data analysis. It should be noted that, due to limitations of resolution, we could only differentiate some $b$ and $c$ peaks in our $2 \mathrm{D}$ NMR experiments. Hence, we mostly refer to $s$ and i domains below, except when otherwise indicated.

(a)

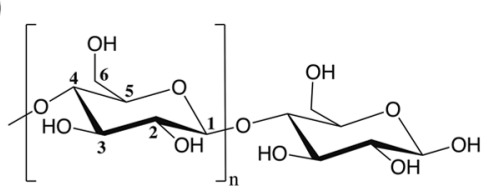

(b)

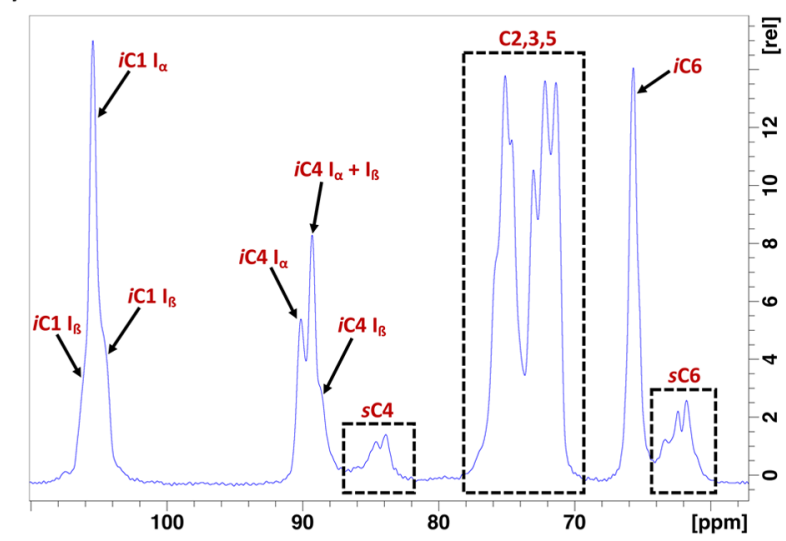

(c)

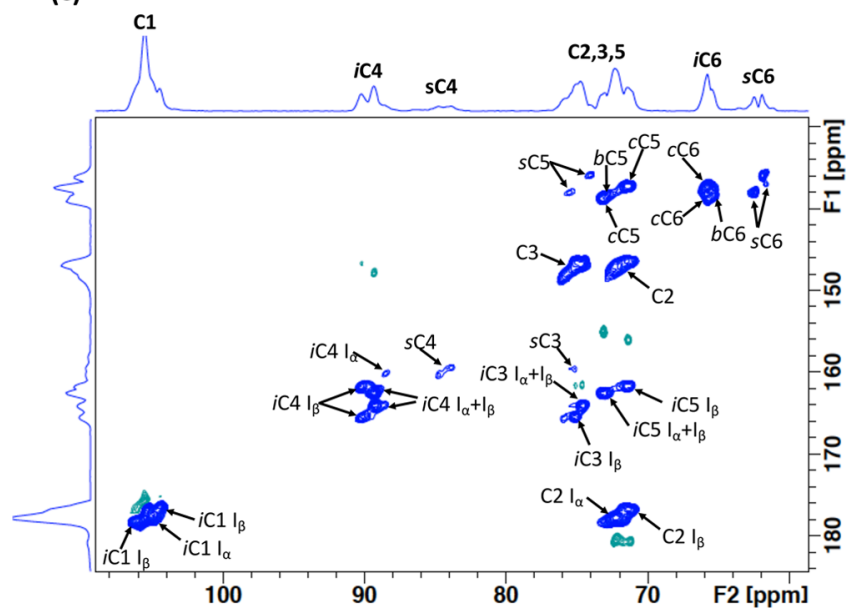

Figure 3. (a) Chemical structure of $\mathrm{BC}$ chains. (b) ${ }^{1} \mathrm{H}-{ }^{13} \mathrm{C} C P / \mathrm{MAS}$ NMR spectrum of ${ }^{13} \mathrm{C}$-labelled $\mathrm{BC}$ gel, acquired at room temperature, $20.0 \mathrm{~T}$ and $12 \mathrm{kHz}$ MAS spinning rate. (c) $2 \mathrm{D}{ }^{13} \mathrm{C}-{ }^{13} \mathrm{C} \mathrm{CP}-$ RINADEQUATE spectrum of ${ }^{13} \mathrm{C}$-labelled $\mathrm{BC}$ gel, acquired at room temperature, $20.0 \mathrm{~T}$ and $12 \mathrm{kHz}$ MAS spinning rate. A $2 \tau$ spin-echo evolution time for a $(\tau-\pi-\tau)$ spin-echo of $5 \mathrm{~ms}$ was employed.

Figure 3 shows the ${ }^{1} \mathrm{H}-{ }^{13} \mathrm{C} \mathrm{CP} / \mathrm{MAS}$ NMR spectrum of ${ }^{13} \mathrm{C}$-labelled BC hydrogel. The following structural features were identified in line with the previous literature: ${ }^{38}$ (i) carbons 4 and 6 showed differentiated peaks for both interior (89.8 and $65.7 \mathrm{ppm}$ for iC4 and iC6, respectively) and surface (84.3 and $62.4 \mathrm{ppm}$ for sC4 and sC6, respectively) domains, and (ii) different chemical environments were observed for $\mathrm{iC} 1$ and $\mathrm{iC} 4$ peaks, corresponding to the $I_{\alpha}(105.4 \mathrm{ppm}$ for $\mathrm{C} 1$ and $90.1 \mathrm{ppm}$ for $\mathrm{C} 4$ ) and $I_{\beta}$ (106.3 and $104.5 \mathrm{ppm}$ for $\mathrm{C} 1$, and $88.6 \mathrm{ppm}$ for $\mathrm{C} 4$ ) allomorphs. For the two C2,3,5 multiplets (centered at 75.2 and $72.2 \mathrm{ppm}$ ), surface and interior domains could not be assigned in the $1 \mathrm{D}{ }^{13} \mathrm{C}$ spectra. However, ${ }^{13} \mathrm{C}-{ }^{13} \mathrm{C}$ SQ-DQ refocused CP-INADEQUATE experiments acquired at ultra-high field allowed us to further assign interior and surface peaks and, in some cases, to differentiate between core and surface-bound peaks (Figures 3 and S9-S11). To the best of our knowledge, the level of detail in ${ }^{13} \mathrm{C}-{ }^{13} \mathrm{C} \mathrm{CP}$ RINADEQUATE spectrum of a $\mathrm{BC}$ hydrogel is unprecedented, ${ }^{39}$ allowing for the first time the differentiation of the surface and interior chemical environments for C3 and C5 (Figures 3 and S9-S11).

Because particle-particle interactions (i.e., surface-surface interactions) together with particle-water interactions determine the mechanical properties of cellulose hydrogels, ${ }^{1,40,41}$ it is important to experimentally estimate the surface area of $\mathrm{BC}$ particles. This can be achieved by calculating the surface-tointerior ratio (s/i) of BC within different gel structures (eq 2). Thus, by determining the impact of XG, AX, and MLG on the s/i ratio of $\mathrm{BC}$, we can attempt to establish correlations with their macroscopic properties. ${ }^{41}$ The deconvolution of the $\mathrm{C} 4$ and $\mathrm{C}^{\prime}$ peaks of quantitative ${ }^{13} \mathrm{C}\left\{{ }^{1} \mathrm{H}\right\}$ DP NMR spectra showed a large increase in the $\mathrm{s} / \mathrm{i}$ ratio for $\mathrm{BC}-\mathrm{XG}$ compared to the pure $\mathrm{BC}$, as shown previously, ${ }^{13}$ while no significant differences were observed for BC-AX and BC-MLG (Table 3, Figure S12). This finding is supported by previous studies,

Table 3. Surface-to-Interior Ratio $(\mathrm{s} / \mathrm{i})$ and Percentage of $I_{\alpha}$ Allomorph (\% $\left.I_{\alpha}\right)$ Obtained by Spectral Deconvolution of iC4 and sC4 Peaks from Quantitative ${ }^{13} \mathrm{C}\left\{{ }^{1} \mathrm{H}\right\}$ DP NMR Spectra $(9.4 \mathrm{~T})$ and ${ }^{1} \mathrm{H}-{ }^{13} \mathrm{C} \mathrm{CP}$ Spectra $(20 \mathrm{~T})$ of ${ }^{13} \mathrm{C}$ Labeled BC Gels

$\begin{array}{lllcc} & \text { BC } & \text { BC-XG } & \text { BC-AX } & \text { BC-MLG } \\ \mathrm{s} / \mathrm{i} & 1: 4.1 & 1: 2.9 & 1: 3.8 & 1: 3.8 \\ \% I_{\alpha} & 64 \% & \ll 64 \%^{a} & 60 \% & 56 \%\end{array}$

${ }^{a}$ The $\% I_{\alpha}$ of BC-XG had to be qualitatively estimated from the CP spectrum on the unlabelled gel due to much greater broadening of the ${ }^{13} \mathrm{C}$-labeled gel spectrum precluding the differentiation of $I_{\alpha}$ and $I_{\beta}$ peaks (Figure S13).

has been suggested to indicate that AX and MLG are physically adsorbed onto the surface of $\mathrm{BC}$, and are not involved in the fiber assembly. ${ }^{9,21,42}$ The increased stiffness of BC-XG reported by AFM correlates with the increased surface of $B C$ fibers, possibly due to the interaction of $\mathrm{XG}$ with $\mathrm{BC}$ chains during assembly. ${ }^{10,13}$

On the other hand, previous works have suggested that $\mathrm{XG}$ interactions with $\mathrm{BC}$ lead to the conversion of $\mathrm{BC} I_{\alpha}$ domains into $I_{\beta}{ }^{10}$ Hence, the percentage of $I_{\alpha}$ allomorph $\left(\% I_{\alpha}\right)$ was calculated from deconvolution of the $\mathrm{iC} 4$ peak (eq 3) on ${ }^{1} \mathrm{H}-{ }^{13} \mathrm{C} \mathrm{CP}$ spectra of ${ }^{13} \mathrm{C}$-labelled $\mathrm{BC}, \mathrm{BC}-\mathrm{AX}$, and $\mathrm{BC}-$ MLG gels acquired at $20 \mathrm{~T}$. For ${ }^{13} \mathrm{C}$-labeled $\mathrm{BC}-\mathrm{XG}$ gel, however, the large spectral broadening due to strong ${ }^{13} \mathrm{C}$ homonuclear dipolar coupling precluded the differentiation of $I_{\alpha}$ and $I_{\beta}$ peaks (Figure S13). Thus, we acquired the CP spectrum for the unlabeled gel (Figure S13). While global spectral deconvolution (GSD) worked $I_{\alpha}$ and $I_{\alpha}+I_{\beta}$ peaks, it was not successful on the $I_{\beta}$ peak due to large broadening. Despite these limitations with the quantification of $\% I_{\alpha}$, the visual comparison of the $\mathrm{iC} 4$ peak of the four gels clearly shows 
a large reduction in the $I_{\alpha}$ peak and an increase of $I_{\beta}$ for BCXG (Figure S13). Notably, the conversion of $I_{\alpha}$ into the lower energy $I_{\beta}$ state $^{43}$ has been previously reported for BC-XG. ${ }^{10,13}$ The ability of XG to alter $\mathrm{BC}$ allomorphism has been related to direct association with cellulose chains close to the point of deposition before mature fibrillar ribbons are formed. ${ }^{13}$ On the other hand, a decrease in $\% I_{\alpha}$ was observed for BC-AX $(60 \%)$ and $\mathrm{BC}-\mathrm{MLG}(56 \%)$ with respect to BC (64\%). However, visual comparison of the spectra (Figure S13) suggests that these differences are not large enough to confidently make a statement on the effect of AX and MLG on BC allomorphism.

Molecular Level Interactions between $B C$ and $X G .{ }^{1} \mathrm{H}-{ }^{13} \mathrm{C}$ CP NMR spectra were acquired at ultra-high field for all ${ }^{13} \mathrm{C}$ labeled $\mathrm{BC}$ hydrogels. $\mathrm{BC}, \mathrm{BC}-\mathrm{AX}$, and $\mathrm{BC}-\mathrm{MLG}$ composites (Figure 4) showed similar linewidths, which is in agreement

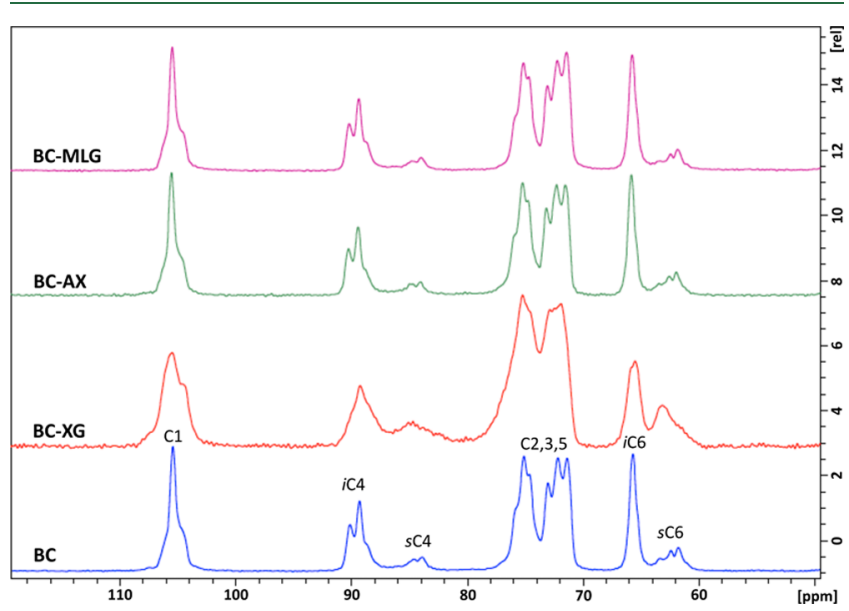

Figure 4. Comparison of the ${ }^{1} \mathrm{H}-{ }^{13} \mathrm{C}$ CP MAS NMR spectra of the ${ }^{13} \mathrm{C}$-labeled hydrogels acquired at $20.0 \mathrm{~T}, 12 \mathrm{kHz}$ MAS, $1 \mathrm{~ms}$ contact time, and $2 \mathrm{~s}$ relaxation delay. The spectrum of $\mathrm{BC}-\mathrm{XG}$ (red line) shows much broader peaks than the other 3 hydrogels, indicating intimate interactions between $\mathrm{BC}$ and $\mathrm{XG}$.

with $\mathrm{AX}$ and MLG not interfering significantly with the ordering of $\mathrm{BC}$ (Table 3) and with previously proposed models of physical adsorption of AX and MLG to the surface of BC particles. ${ }^{9,21}$ Importantly, the ${ }^{1} \mathrm{H}-{ }^{13} \mathrm{C} \mathrm{CP}$ and CPSP spectra of unlabeled $\mathrm{BC}-\mathrm{MLG}$ showed peaks corresponding to $\mathrm{C} 6$ of $\beta(1-3)$ chains of MLG at 50.5, 60.2, and $60.9 \mathrm{ppm}$ [Figure 5b, A6(1), A6(2), and A6(3) peaks, respectively]. ${ }^{33}$ Spectral deconvolution of the A6(3) peak in both CP and CPSP spectra indicated that the CP contribution accounts for about $30 \%$ of the total A6(3) peak area (CPSP spectrum). Hence, we can roughly estimate that about $30 \%$ of MLG present in our BC-MLG gels is tightly bound to BC, although this value should be cautiously taken as the CPSP experiments were not optimized for quantitative measurements.

On the other hand, the ${ }^{1} \mathrm{H}-{ }^{13} \mathrm{C} \mathrm{CP} /$ MAS NMR spectrum of ${ }^{13} \mathrm{C}-\mathrm{BC}-\mathrm{XG}$ showed much broader peaks (Figure 4 ), as previously reported. ${ }^{8}$ It is important to note that this effect is not due to both $\mathrm{BC}$ and $\mathrm{XG}$ contributions to the spectra as only $\mathrm{BC}$ is ${ }^{13} \mathrm{C}$-labeled. The peaks of unlabeled $\mathrm{XG}$, which is a minor component of the composite (14\% wt/wt; Table 2$)$, are within the noise level. Notably, the ${ }^{1} \mathrm{H}-{ }^{13} \mathrm{C} \mathrm{CP} / \mathrm{MAS}$ NMR spectrum of unlabeled $\mathrm{BC}-\mathrm{XG}$ gel also showed broader $\mathrm{BC}$ peaks (Figure 5a). This is in agreement with previous literature showing that a fraction of XG intercalates between individual $\mathrm{BC}$ chains via strong molecular association with forming fibrils

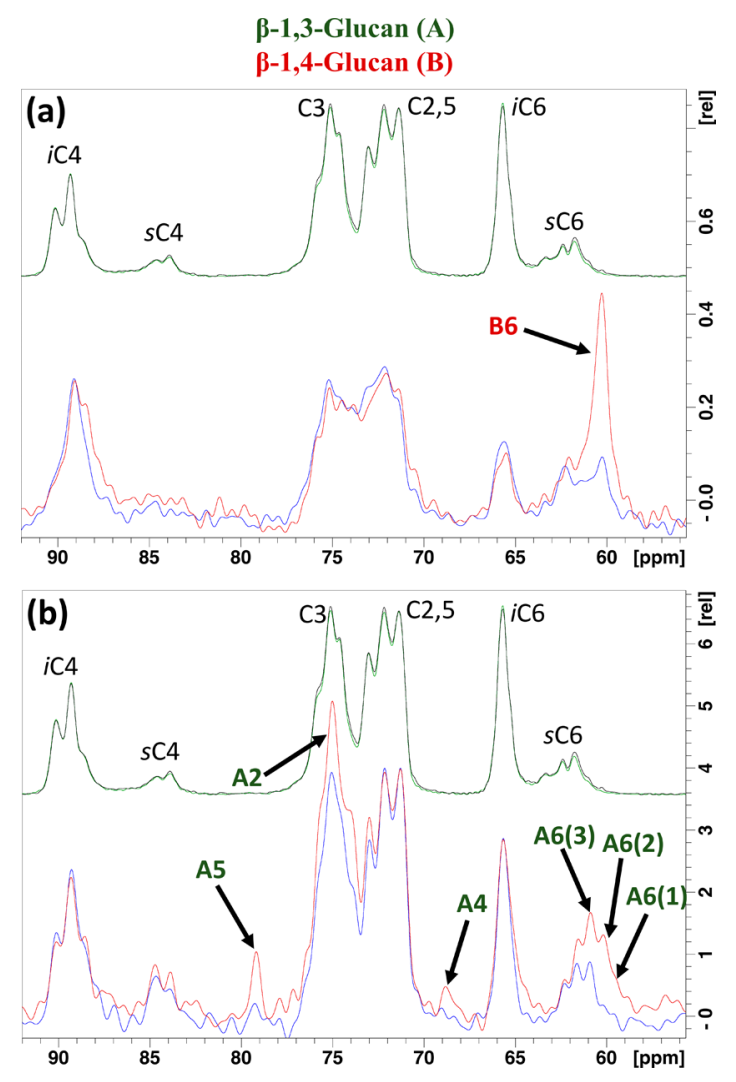

Figure 5. Comparison of ${ }^{1} \mathrm{H}-{ }^{13} \mathrm{C} \mathrm{CP}$ (blue line) and CPSP (red line) NMR spectra of unlabeled $\mathrm{BC}$ composite hydrogels with (a) XG and (b) MLG. The CP and CPSP spectra of ${ }^{13} \mathrm{C}$-labeled BC hydrogels are shown as green and black lines, respectively, for comparison. The assignment of mobile XG and MLG peaks are indicated with arrows. All spectra were acquired at a ${ }^{13} \mathrm{C}$ frequency of $213.8 \mathrm{MHz}$. For the purpose of clarity, the anomeric carbons are not shown in the spectra due to the very broad distribution of mobile $\mathrm{C} 1$ peaks of $\mathrm{BC}$ present in the CPSP spectrum.

prior to their assembly into the final ribbon-shaped fibers. ${ }^{13}$ The strong association between $\mathrm{BC}$ and $\mathrm{XG}$ could lead to broader $\mathrm{BC}$ peaks via (i) shorter $\mathrm{T}_{2}$ times of $\mathrm{BC}$ and/or, most likely, (ii) increased disordered of $\mathrm{BC}$ fibrils as shown above (Table 3). One XG peak corresponding to C6 was observed in both CP an CPSP spectra (B6 peak at $60.3 \mathrm{ppm}$ in Figure 5a). As the CP contribution accounts for about $45 \%$ of the total B6 peak area (CPSP spectrum), we can roughly estimate that about $45 \%$ of the total XG is bound to BC.

Dynamic Regimes in BC Composite Hydrogels. Global and local dynamics are key features to understand the structural and binding properties of biomolecules. However, the broad distribution of time scales of molecular motions that might occur in complex systems require to tackle them using several approaches specific for different time scales. We have employed (i) the ${ }^{1} \mathrm{H}-{ }^{13} \mathrm{C} \mathrm{CP}$ kinetics approach to probe for slow motions within the millisecond-to-second time scale, and (ii) ${ }^{13} \mathrm{C}\left\{{ }^{1} \mathrm{H}\right\}$ DP with short recycle delay and CPSP experiments to monitor the fast motions (faster than the millisecond time scale) of the surface domains of $\mathrm{BC}$ and the hemicelluloses, respectively.

$\mathrm{CP}$ kinetics analysis demonstrated the presence of very rigid domains in $\mathrm{BC}, \mathrm{BC}-\mathrm{AX}$, and $\mathrm{BC}-\mathrm{XG}$ (very short $T_{\mathrm{CH}}$ and very long ${ }^{1} \mathrm{H} \quad T_{1 \rho}$, Tables 4 and $\left.S 4\right)$. Interestingly, this observation not only applies for the interior but also for the 
Table 4. $T_{\mathrm{CH}}$ Parameter and Surface Mobility Index $\left(\mathrm{MI}_{\mathrm{S}}\right)$ for the Anomeric Carbon Peak of $\mathrm{BC}^{a}$

$\begin{array}{lcc} & T_{\mathrm{CH}}(\mu \mathrm{s}) & \mathrm{MI}_{\mathrm{S}}(\%) \\ \text { BC } & 45.2( \pm 2.8) & 79 \\ \text { BC-XG } & 40.3( \pm 2.4) & 92 \\ \text { BC-AX } & 38.7( \pm 2.1) & 67 \\ \text { BC-MLG } & 279( \pm 32) & 82\end{array}$

${ }^{a}$ These were derived from CP kinetics build-up curves and mobilityenhanced ${ }^{13} \mathrm{C} \mathrm{DP}$ experiments, acquired at $100 \mathrm{MHz}{ }^{13} \mathrm{C}$ frequency. The MIs values were calculated from spectral deconvolution of the $\mathrm{sC} 4$ and $\mathrm{iC} 4$ peak areas.

surface regions. We could speculate that this population of highly rigid surface domains might represent the areas of fibril-fibril interactions, where the conformational dynamics of the surface chains of $\mathrm{BC}$ is restricted. ${ }^{1} \mathrm{H} \mathrm{T} \mathrm{T}_{1 \rho}$ times of $\mathrm{BC}$ could not be determined accurately from $\mathrm{CP}$ kinetics build-up curves due to extremely slow ${ }^{1} \mathrm{H} T_{1 \rho}$ relaxation compared to the longer CP contact time probed $(6 \mathrm{~ms})$, but we can reliably claim that they are at least longer than $100 \mathrm{~ms}$ (Tables 4 and S4, Figures S15-S22). For BC-MLG, the experimental $T_{\mathrm{CH}}$ value was about 6-7 times longer for all $\mathrm{BC}$ peaks (Tables 4 and S4), hence proving the presence of less rigid $\mathrm{BC}$ interior and surface domains in the presence of MLG (partial averaging of dipolar interactions). This is in agreement with the AFM results, which showed that BC-MLG composite gels are structurally weaker than BC-only gels (Figures 2 and S4-S7).

${ }^{13} \mathrm{C}\left\{{ }^{1} \mathrm{H}\right\}$ DP NMR experiments using a very short relaxation delay ( $1 \mathrm{~s}$ ) allowed for the characterization of very mobile BC surface domains present in all gels. ${ }^{33}$ The surface-to-interior mobility of BC increased in the presence of XG (MI from 79 to $92 \%$ ), decreased for BC-AX (MI from 79 to $67 \%$ ), and no significant change was observed for BC-MLG (Table 4, Figure S14). This is in agreement with the proposed intercalating interactions between $\mathrm{BC}$ and $\mathrm{XG}$ leading to a larger partially disordered surface (Table 3). ${ }^{1}$ The MI reduction observed for $\mathrm{BC}-\mathrm{AX}$ might be due to coating of $\mathrm{BC}$ ribbons' surfaces by amorphous $\mathrm{AX}$ chains, as previously proposed. ${ }^{1}$

While ${ }^{13} \mathrm{C}$-labeling of $\mathrm{BC}$ is a very powerful approach for the detailed characterization of BC hydrogels, it has the disadvantage of hiding the spectral features of other nonlabeled components (e.g. hemicelluloses) present in composite hydrogels. Aiming to characterize XG and MLG in our gels, we carried out CP and CPSP experiments for unlabeled BC$\mathrm{XG}$ and $\mathrm{BC}-\mathrm{MLG}$ hydrogels at ultra-high field $(20 \mathrm{~T})$. It should be noted that MLG and XG hemicellulose components are more mobile compared to BC fibers (Figure 5; iC4 and iC6 peaks of BC compared to MLG and XG peaks in the CPSP spectra). The dynamics of $\mathrm{BC}$ particles would lie within the ms-to-s timescale, as shown by CP kinetics (Tables 4 and S4). On the other hand, the $\mathrm{B} 6$ peak $(60.3 \mathrm{ppm})$, corresponding to C6 of XG $\beta-1,4$ chains, was observed with increased intensity in the CPSP spectrum of BC-XG gel (Figure 5a). As this peak was also visible in the $\mathrm{CP}$ spectrum (Figure 5a), we can roughly estimate an intermediate mobility regime ( $\mu$ s-to-ms time scale) for $\mathrm{XG}$ in $\mathrm{BC}-\mathrm{XG}$ gels. $\mathrm{XG}$ is known to establish strong molecular association with nascent cellulose fibrils prior to the formation of the final ribbon-shaped fiber but also to be located at the surface of $\mathrm{BC}$ fibrils and act as a physical crosslinker. ${ }^{1,10,13}$ This population of surface XG might be responsible of the mobility-enhanced intensity of the B6 peak (Figure 5a).

In addition, three peaks attributable to mobile domains were identified in the CPSP spectrum of unlabeled BC-MLG gel within the expected chemical shift region for C6 of MLG $\beta-1,3$ chains. ${ }^{33}$ In particular, (i) a very mobile fraction at $59.6 \mathrm{ppm}$ [Figure 5b, peak A6(1); no CP intensity, $\mu$ s-to-ns time scale], (ii) a mobile population at $60.2 \mathrm{ppm}$ [Figure 5b, peak A6(2); very small CP intensity, $\mu$ s-to-ns time scale], and (iii) a population of intermediate mobility at $60.9 \mathrm{ppm}$ [Figure $5 \mathrm{~b}$, peak A6(3); high CP intensity, ms-to- $\mu$ s time scale]. To our knowledge, these peaks have never been individually assigned; however, due to their differences in mobility, we could speculate that they might correspond to different populations of BC-bound and free MLG. Another two very mobile peaks of MLG can be observed at 79.2 (C5) and $68.9 \mathrm{ppm}$ (C4) in the CPSP spectrum only, in agreement with NMR assignment of fungal cell walls. ${ }^{33}$ Also, despite complete overlapping with BC peaks, the mobile peak observed at $75.1 \mathrm{ppm}$ matches the expected chemical shift for C2 of $\beta-1,3$ chains of MLG. ${ }^{33}$

Probing Water-BC Interactions by WPT-CP NMR. ${ }^{1} \mathrm{H}-{ }^{13} \mathrm{C}$ WPT-CP represents a very powerful technique for monitoring interactions of water to cellulose particles at atomic resolution, as it has been previously shown for PCWs. ${ }^{34}$ Also, WPT-CP build-up curves can indirectly report on the architecture of cellulose composites and thus provide structural insights on their function. ${ }^{34}$ Recently, Kang et al. used 2D water-edited ${ }^{13} \mathrm{C}-{ }^{13} \mathrm{C}$ correlation $\mathrm{CP}$ experiments to show that polysaccharides containing $\beta$ - $(1-3), \beta-(1-4)$, and $\beta-(1-6)$ glucans are better hydrated than $\alpha-(1-3)$ glucans and chitin in fungal cell walls. ${ }^{33}$ However, they could not identify either the influence of cell walls polysaccharides on the hydration properties of $\mathrm{BC}$ or the specific polysaccharides presenting increased hydration. By carrying out WPT-CP experiments at different mixing times on pure ${ }^{13} \mathrm{C}$-labelled $\mathrm{BC}$ gels and composites with either XG, AX, or MLG, we have been able to characterize to which extent individual PCW polysaccharides affect the hydration of BC. It should be highlighted that, strictly speaking, WPT-CP curves report only on water interactions to rigid components as it relies on CP. Hence, the interactions of water molecules to the very mobile components present in $\mathrm{BC}$ gels (Table 4, $\mathrm{MI}_{\mathrm{s}}$; Figure 5) would be mostly invisible in WPT-CP experiments. The WPT$\mathrm{CP}$ build-up curves acquired for the four ${ }^{13} \mathrm{C}$-labeled BC gels showed that $\mathrm{BC}$ fibrils hold a higher population of bound water molecules (faster WPT-CP growth) in the presence of XG and MLG but not AX (Figures 6 and S23-S28). The latter did not exert a significant effect on BC hydration in comparison to the control sample ( $\mathrm{BC}$ only gel). This is hence in qualitative agreement with the data reported for fungal cell walls, which further validates the use of $\mathrm{BC}$ hydrogels as ideal mimics of PCWs. BC-XG and BC-MLG gels featured the shortest lag phase followed by a very fast build-up. This indicates closer proximity of water to the surface of $\mathrm{BC}$ fibrils and more efficient spin diffusion transfer at the BC-water interface (Figures 6 and S23-S28). The increased hydration of $\mathrm{BC}-\mathrm{XG}$ gels is in agreement with our thermogravimetric analyses, showing a higher temperature of complete water loss for this gel (Tables 2 and S2), and correlates with the larger surface area of BC fibers (Table 3, s/ i) and greater mobility of BC surface domains (Table 4, $\mathrm{MI}_{\mathrm{s}}$ ). Hence, the effect of XG on the surface properties of BC fibrils 


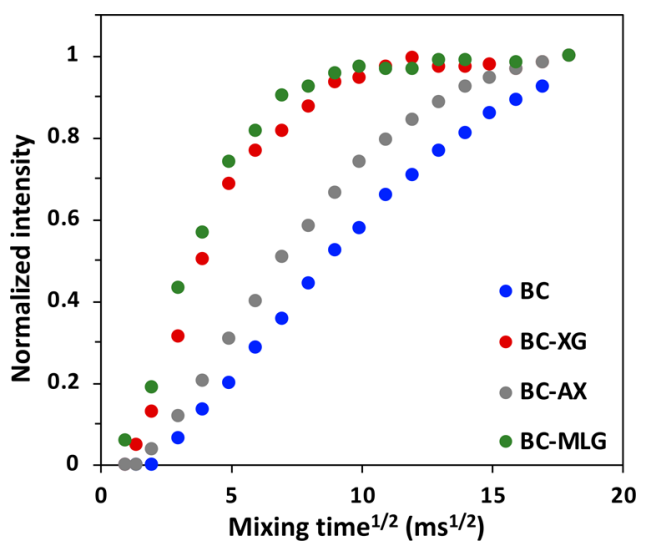

Figure 6. Normalized water spin diffusion build-up curves of the anomeric carbon for BC (blue dots), BC-XG (red dots), BC-AX (grey dots), and BC-MLG (green dots).

is possibly responsible for the increased population of bound water contained in $\mathrm{BC}-\mathrm{XG}$ gels.

For BC-MLG gels, the growth of the WPT-CP curves is similar to BC-XG (Figure 6), which correlates with a similar temperature of complete water loss (Tables 2 and S2). Unlike $\mathrm{XG}$, it has been previously shown that MLG does not bind BC chains during the fibril assembly but adsorbs onto the already formed fibrils. ${ }^{9,21}$ Also, the presence of MLG did not impact either the surface ratio (Table 3 ) or mobility of the $\mathrm{BC}$ surface (Table 4). Thus, the increased binding of water to BC in BCMLG gels is probably due to the greater hydrophilic nature of MLG increasing the fraction of structured water readily available for binding BC fibers. In this regard, our WPT-CP data further support the previously suggested mechanism of physical adsorption of the very hydrophilic MLG onto the surface of BC particles, where MLG would act as a "coating agent" of $\mathrm{BC}$ particles and as a source of prestructured water ready to interact with $\mathrm{BC}$, thus reducing the entropic penalty of water-BC interactions. ${ }^{9}$

Table 5 shows a qualitative summary of the macroscopic and molecular scale features determined for the three $\mathrm{BC}$ composites in comparison with the BC-only hydrogel. BC$\mathrm{AX}$ and $\mathrm{BC}$ presented a very similar macroscopic behavior, and

Table 5. Summary of the Macroscopic and Molecular Features Measured for BC-AX, BC-XG, and BC-MLG Composites with Respect to BC Only Gels ${ }^{a}$

\begin{tabular}{|c|c|c|c|}
\hline & $\mathrm{BC}-\mathrm{AX}$ & $\mathrm{BC}-\mathrm{XG}$ & $\mathrm{BC}-\mathrm{MLG}$ \\
\hline \multicolumn{4}{|c|}{ Macroscopic Features } \\
\hline stiffness & $\sim$ & $\sim$ & $\downarrow$ \\
\hline order & $\sim$ & $\downarrow \downarrow$ & $\downarrow$ \\
\hline moisture content & $\sim$ & $\sim$ & $\sim$ \\
\hline $\begin{array}{l}\text { temperature at point of complete water } \\
\text { loss }\left({ }^{\circ} \mathrm{C}\right)\end{array}$ & $\sim$ & $\uparrow$ & $\uparrow$ \\
\hline \multicolumn{4}{|c|}{ Molecular Features } \\
\hline$\% I_{\alpha}$ & $\sim$ & $\downarrow$ & $\downarrow$ \\
\hline $\mathrm{s} / \mathrm{i}$ ratio & $\sim$ & $\uparrow$ & $\sim$ \\
\hline s/i mobility & $\downarrow$ & $\uparrow$ & $\sim$ \\
\hline mobility of BC ribbons & $\sim$ & $\sim$ & $\uparrow$ \\
\hline${ }^{13} \mathrm{C}$ peak broadening & $\sim$ & $\uparrow$ & $\sim$ \\
\hline bound water & $\sim$ & $\uparrow$ & $\uparrow$ \\
\hline
\end{tabular}

this correlates with minor changes at the molecular scale. On the other hand, the reduced stiffness of BC-MLG composites and the differences in the macroscopic order and population of bound water observed for BC-XG and BC-MLG gels demonstrate the different mechanisms which can influence the gel structure. Reduced cellulose order does not directly influence cellulose gel fiber stiffness, which is instead related to $\mathrm{BC}$ ribbon mobility within the gel.

\section{CONCLUSIONS}

The combined analysis of AFM, XRD, TGA, and solid-state NMR data has provided insights into the complex structural features governing the properties of cellulose hydrogels forming composites with different polysaccharides. The use of mobility-enhanced NMR methods together with water polarization transfer NMR experiments allowed us to differentiate core, surface-bound, and surface domains present in BC.

Our results indicate that $\mathrm{BC}$ ribbons are formed with increased long-range disorder when produced in the presence of XG-containing media, giving hydrogels with similar mechanical properties to BC-only gels (Table 5). At the molecular level, this is related to specific $\mathrm{BC}-\mathrm{XG}$ interactions (strong peak broadening), greater $\mathrm{BC}$ surface area and surface mobility, and increased BC-bound water (Table 5). We propose that the association between $\mathrm{BC}$ and $\mathrm{XG}$ during fibril assembly increases gel disorder, giving rise to a looser fibrillar packing. Although it is tempting to correlate reduced network particle density to weaker gels, the increased population of bound water contained in BC-XG gels might compensate for the effect of looser fibril network on gel strength.

For the first time, we report that high molecular weight MLG increases long-range disorder in BC, producing weaker BC hydrogels. However, MLG did not affect the surface area of $\mathrm{BC}$ ribbons but it increased their mobility and boosted water interactions with the fibrillar network. This is in agreement with the previously proposed mechanism of MLG physical adsorption onto the surface of $\mathrm{BC}$, reducing the entropic penalty of $\mathrm{BC}$-water interactions via MLG-mediated preorganization of bound water. The use of high molecular weight MLG represents an unexplored opportunity to generate hydrogels with tailored properties by acting as a hydration and mechanical modulator of BC-based materials, opening the possibility to generate biocompatible BC-based hydrogels with tuneable hydration and water holding properties for different applications.

\section{ASSOCIATED CONTENT}

\section{S Supporting Information}

The Supporting Information is available free of charge on the ACS Publications website at DOI: 10.1021/acs.biomac.9b01070.

Gel thickness, TGA, PXRD, SEM, AFM, rheology, and NMR spectra and data analysis (PDF)

\section{AUTHOR INFORMATION}

\section{Corresponding Authors}

*E-mail: fred.warren@quadram.ac.uk (F.J.W.).

*E-mail: y.khimyak@uea.ac.uk (Y.Z.K.).

ORCID

Andrew N. Round: 0000-0001-9026-0620

Frederick J. Warren: 0000-0002-2512-4670 
Yaroslav Z. Khimyak: 0000-0003-0424-4128

\section{Present Address}

${ }^{\perp}$ Environmental Epigenetics and Genetics Group, Department of Horticulture, College of Agriculture, Food and Environment, University of Kentucky, Lexington, Kentucky, USA.

\section{Notes}

The authors declare no competing financial interest.

\section{ACKNOWLEDGMENTS}

The authors thank Shiyi Lu and Francesca Sonni (both University of Queensland) for technical assistance with monosaccharide analysis and Kathryn Cross (Quadram Institute) for assistance with sample preparation and imaging (SEM). The UK $850 \mathrm{MHz}$ solid-state NMR Facility used in this research was funded by EPSRC and BBSRC (contract reference PR140003), as well as the University of Warwick including via part funding through Birmingham Science City Advanced Materials Projects 1 and 2 supported by Advantage West Midlands (AWM) and the European Regional Development Fund (ERDF). F.J.W. and Y.Z.K. would like to acknowledge the support of a Norwich Research Park Science Links Seed Fund. The Engineering and Physical Sciences Research Council (EPSRC) is acknowledged for provision of financial support (EP/N033337/1) for J.C.M.-G. and Y.Z.K. We are also grateful for UEA Faculty of Science NMR facility. F.J.W. and K.R.C. gratefully acknowledge the support of the Biotechnology and Biological Sciences Research Council (BBSRC); this research was funded by the BBSRC Institute Strategic Programme Food Innovation and Health BB/ R012512/1 and its constituent projects BBS/E/F/ 000PR10343 and BBS/E/F/000PR10346. T.K. would like to thank the support of a Quadram Institute Bioscience sponsored $\mathrm{PhD}$ scholarship. V.G. would like to acknowledge the support of BBSRC Norwich Research Park Bioscience Doctoral Training Grant (BB/M011216/1).

\section{REFERENCES}

(1) Martínez-Sanz, M.; Gidley, M. J.; Gilbert, E. P. Hierarchical Architecture of Bacterial Cellulose and Composite Plant Cell Wall Polysaccharide Hydrogels Using Small Angle Neutron Scattering. Soft Matter 2016, 12, 1534-1549.

(2) Kim, Y.-H.; Park, S.; Won, K.; Kim, H. J.; Lee, S. H. Bacterial Cellulose-Carbon Nanotube Composite as a Biocompatible Electrode for the Direct Electron Transfer of Glucose Oxidase. J. Chem. Technol. Biotechnol. 2013, 88, 1067-1070.

(3) Yoon, S. H.; Jin, H.-J.; Kook, M.-C.; Pyun, Y. R. Electrically Conductive Bacterial Cellulose by Incorporation of Carbon Nanotubes. Biomacromolecules 2006, 7, 1280-1284.

(4) Shao, Y.; Chaussy, D.; Grosseau, P.; Beneventi, D. Use of Microfibrillated Cellulose/Lignosulfonate Blends as Carbon Precursors: Impact of Hydrogel Rheology on 3D Printing. Ind. Eng. Chem. Res. 2015, 54, 10575-10582.

(5) Zhao, J.; Zheng, K.; Nan, J.; Tang, C.; Chen, Y.; Hu, Y. Synthesis and Characterization of Lignosulfonate-Graft-Poly (Acrylic Acid)/ Hydroxyethyl Cellulose Semi-Interpenetrating Hydrogels. React. Funct. Polym. 2017, 115, 28-35.

(6) Shao, Y.; Guizani, C.; Grosseau, P.; Chaussy, D.; Beneventi, D. Thermal Characterization and Kinetic Analysis of Microfibrillated Cellulose/Lignosulfonate Blends. J. Anal. Appl. Pyrolysis 2017, 124, $25-34$.

(7) Alonso, E.; Faria, M.; Mohammadkazemi, F.; Resnik, M.; Ferreira, A.; Cordeiro, N. Conductive Bacterial Cellulose-Polyaniline Blends: Influence of the Matrix and Synthesis Conditions. Carbohydr. Polym. 2018, 183, 254-262.
(8) Lopez-Sanchez, P.; Cersosimo, J.; Wang, D.; Flanagan, B.; Stokes, J. R.; Gidley, M. J. Poroelastic Mechanical Effects of Hemicelluloses on Cellulosic Hydrogels under Compression. PLoS One 2015, 10, No. e0122132.

(9) Mikkelsen, D.; Flanagan, B. M.; Wilson, S. M.; Bacic, A.; Gidley, M. J. Interactions of Arabinoxylan and $(1,3)(1,4)-\beta$-Glucan with Cellulose Networks. Biomacromolecules 2015, 16, 1232-1239.

(10) Whitney, S. E. C.; Wilson, E.; Webster, J.; Bacic, A.; Reid, J. S. G.; Gidley, M. J. Effects of Structural Variation in Xyloglucan Polymers on Interactions with Bacterial Cellulose. Am. J. Bot. 2006, 93, $1402-1414$.

(11) Jia, Y.; Wang, X.; Huo, M.; Zhai, X.; Li, F.; Zhong, C. Preparation and Characterization of a Novel Bacterial Cellulose/ Chitosan Bio-Hydrogel. Nanomater. Nanotechnol. 2017, 7, 184798041770717.

(12) Carpita, N.; Gibeaut, D. Structural Models of Primary Cell Walls in Flowering Plants: Consistency of Molecular Structure with the Physical Properties of the Walls during Growth. Plant J. 1993, 3, $1-30$.

(13) Whitney, S. E. C.; Brigham, J. E.; Darke, A. H.; Reid, J. S. G.; Gidley, M. J. In Vitro Assembly of Cellulose/Xyloglucan Networks: Ultrastructural and Molecular Aspects. Plant J. 1995, 8, 491-504.

(14) Chanliaud, E.; Burrows, K.; Jeronimidis, G.; Gidley, M. Mechanical Properties of Primary Plant Cell Wall Analogues. Planta 2002, 215, 989-996.

(15) Martínez-Sanz, M.; Mikkelsen, D.; Flanagan, B. M.; Rehm, C.; de Campo, L.; Gidley, M. J.; Gilbert, E. P. Investigation of the Microand Nano-Scale Architecture of Cellulose Hydrogels with Plant Cell Wall Polysaccharides: A Combined USANS/SANS Study. Polymer 2016, 105, 449-460.

(16) Chanliaud, E.; Gidley, M. J. In Vitro Synthesis and Properties of Pectin/Acetobacter Xylinus Cellulose Composites. Plant J. 1999, 20, $25-35$.

(17) Park, Y. B.; Lee, C. M.; Kafle, K.; Park, S.; Cosgrove, D. J.; Kim, S. H. Effects of Plant Cell Wall Matrix Polysaccharides on Bacterial Cellulose Structure Studied with Vibrational Sum Frequency Generation Spectroscopy and X-Ray Diffraction. Biomacromolecules 2014, 15, 2718-2724.

(18) Uhlin, K. I.; Atalla, R. H.; Thompson, N. S. Influence of Hemicelluloses on the Aggregation Patterns of Bacterial Cellulose. Cellulose 1995, 2, 129-144.

(19) Whitney, S. E. C.; Brigham, J. E.; Darke, A. H.; Reid, J. S. G.; Gidley, M. J. Structural Aspects of the Interaction of Mannan-Based Polysaccharides with Bacterial Cellulose. Carbohydr. Res. 1998, 307, 299-309.

(20) Lin, D.; Lopez-Sanchez, P.; Gidley, M. J. Interactions of Pectins with Cellulose during Its Synthesis in the Absence of Calcium. Food Hydrocolloids 2016, 52, 57-68.

(21) Kiemle, S. N.; Zhang, X.; Esker, A. R.; Toriz, G.; Gatenholm, P.; Cosgrove, D. J. Role of $(1,3)(1,4)-\beta$-Glucan in Cell Walls: Interaction with Cellulose. Biomacromolecules 2014, 15, 1727-1736.

(22) Martínez-Sanz, M.; Mikkelsen, D.; Flanagan, B.; Gidley, M. J.; Gilbert, E. P. Multi-Scale Model for the Hierarchical Architecture of Native Cellulose Hydrogels. Carbohydr. Polym. 2016, 147, 542-555.

(23) Czaja, W. K.; Young, D. J.; Kawecki, M.; Brown, R. M. The Future Prospects of Microbial Cellulose in Biomedical Applications. Biomacromolecules 2007, 8, 1-12.

(24) Jonas, R.; Farah, L. F. Production and Application of Microbial Cellulose. Polym. Degrad. Stab. 1998, 59, 101-106.

(25) Mikkelsen, D.; Gidley, M. J. Formation of Cellulose-Based Composites with Hemicelluloses and Pectins Using Gluconacetobacter Fermentation BT. In The Plant Cell Wall: Methods and Protocols; Popper, Z. A., Ed.; Humana Press: Totowa, NJ, 2011; pp 197-208.

(26) Villares, A.; Bizot, H.; Moreau, C.; Rolland-Sabaté, A.; Cathala, B. Effect of Xyloglucan Molar Mass on Its Assembly onto the Cellulose Surface and Its Enzymatic Susceptibility. Carbohydr. Polym. 2017, 157, 1105-1112. 
(27) Grundy, M. M.-L.; Quint, J.; Rieder, A.; Ballance, S.; Dreiss, C. A.; Butterworth, P. J.; Ellis, P. R. Impact of Hydrothermal and Mechanical Processing on Dissolution Kinetics and Rheology of Oat $\beta$-Glucan. Carbohydr. Polym. 2017, 166, 387-397.

(28) Pettolino, F. A.; Walsh, C.; Fincher, G. B.; Bacic, A. Determining the Polysaccharide Composition of Plant Cell Walls. Nat. Protoc. 2012, 7, 1590.

(29) Hutter, J. L.; Bechhoefer, J. Calibration of Atomic-force Microscope Tips. Rev. Sci. Instrum. 1993, 64, 1868-1873.

(30) Hertz, H. Ueber Die Berührung Fester Elastischer Körper. J. Reine. Angew. Math. 1882, 1882, 156-171.

(31) Radmacher, M.; Fritz, M.; Hansma, P. K. Imaging Soft Samples with the Atomic Force Microscope: Gelatin in Water and Propanol. Biophys. J. 1995, 69, 264-270.

(32) Meza-Contreras, J. C.; Manriquez-Gonzalez, R.; GutiérrezOrtega, J. A.; Gonzalez-Garcia, Y. XRD and Solid State 13C-NMR Evaluation of the Crystallinity Enhancement of 13C-Labeled Bacterial Cellulose Biosynthesized by Komagataeibacter Xylinus under Different Stimuli: A Comparative Strategy of Analyses. Carbohydr. Res. 2018, 461, 51-59.

(33) Kang, X.; Kirui, A.; Muszyński, A.; Widanage, M. C. D.; Chen, A.; Azadi, P.; Wang, P.; Mentink-Vigier, F.; Wang, T. Molecular Architecture of Fungal Cell Walls Revealed by Solid-State NMR. Nat. Commun. 2018, 9, 2747.

(34) White, P. B.; Wang, T.; Park, Y. B.; Cosgrove, D. J.; Hong, M. Water-Polysaccharide Interactions in the Primary Cell Wall of Arabidopsis Thaliana from Polarization Transfer Solid-State NMR. J. Am. Chem. Soc. 2014, 136, 10399-10409.

(35) Mikkelsen, D.; Gidley, M. J.; Williams, B. A. In Vitro Fermentation of Bacterial Cellulose Composites as Model Dietary Fibers. J. Agric. Food Chem. 2011, 59, 4025-4032.

(36) Dolan, G. K.; Cartwright, B.; Bonilla, M. R.; Gidley, M. J.; Stokes, J. R.; Yakubov, G. E. Probing Adhesion between Nanoscale Cellulose Fibres Using AFM Lateral Force Spectroscopy: The Effect of Hemicelluloses on Hydrogen Bonding. Carbohydr. Polym. 2019, 208, 97-107.

(37) Ioelovich, M. Y. Models of Supramolecular Structure and Properties of Cellulose. Polym. Sci., Ser. A 2016, 58, 925-943.

(38) Wang, T.; Hong, M. Solid-State NMR Investigations of Cellulose Structure and Interactions with Matrix Polysaccharides in Plant Primary Cell Walls. J. Exp. Bot. 2015, 67, 503-514.

(39) Okushita, K.; Komatsu, T.; Chikayama, E.; Kikuchi, J. Statistical Approach for Solid-State NMR Spectra of Cellulose Derived from a Series of Variable Parameters. Polym. J. 2012, 44, 895.

(40) Calabrese, V.; Muñoz-García, J. C.; Schmitt, J.; da Silva, M. A.; Scott, J. L.; Angulo, J.; Khimyak, Y. Z.; Edler, K. J. Understanding Heat Driven Gelation of Anionic Cellulose Nanofibrils: Combining Saturation Transfer Difference (STD) NMR, Small Angle X-Ray Scattering (SAXS) and Rheology. J. Colloid Interface Sci. 2019, 535, 205.

(41) Park, S.; Baker, J. O.; Himmel, M. E.; Parilla, P. A.; Johnson, D. K. Cellulose Crystallinity Index: Measurement Techniques and Their Impact on Interpreting Cellulase Performance. Biotechnol. Biofuels 2010, 3, 10.

(42) Renard, C. M. G. C.; Jarvis, M. C. A Cross-Polarization, MagicAngle-Spinning, 13C-Nuclear-Magnetic-Resonance Study of Polysaccharides in Sugar Beet Cell Walls. Plant Physiol. 1999, 119, 13151322.

(43) López, C. A.; Bellesia, G.; Redondo, A.; Langan, P.; Chundawat, S. P. S.; Dale, B. E.; Marrink, S. J.; Gnanakaran, S. MARTINI Coarse-Grained Model for Crystalline Cellulose Microfibers. J. Phys. Chem. B 2015, 119, 465-473. 